\title{
Microstructure Analysis of Laser Remelting for Thermal Barrier Coatings on the Surface of Titanium Alloy
}

\author{
Bin $\mathrm{LU}^{1, \text { a }}$, Donghong WANG ${ }^{1, \mathrm{~b}}$, Lv XIAO ${ }^{2, \mathrm{c}}, \mathrm{Fei}^{3, \mathrm{~d}}$, Jixuan REN ${ }^{1, \mathrm{e}}$ \\ Liangliang $\mathrm{LI}^{1, \mathrm{f}}$ and Wenyun $\mathrm{WU}^{1, \mathrm{~g}}$ \\ ${ }^{1}$ School of Materials Engineering, Shanghai University of Engineering Science, Shanghai, \\ 201620, China \\ ${ }^{2}$ Shanghai Aerospace Precision Machinery Research Institute, Shanghai 201600, China \\ ${ }^{3}$ State Key Laboratory of Metal Matrix Composites, Shanghai Jiao Tong University, Shanghai, 200240, \\ China \\ a'wdhcet6@163.com, ${ }^{\mathrm{b} *}$ wdh@sues.edu.cn ${ }^{1},{ }^{\mathrm{c}}$ alno_2001_0@163.com, ${ }^{\mathrm{d}}$ lifei@sjtu.edu.cn, \\ erjx@sues.edu.cn, ${ }^{\mathrm{f}}$ lliangliang@sues.edu.cn, ${ }^{\mathrm{g}} \mathrm{wenyun@126.com}$
}

\begin{abstract}
In this paper, the preparation and organization performance of thermal barrier coatings (TCBs) on the surface of titanium were studied experimentally. Nanostructured $8 \mathrm{wt} \%$ yttria partially stabilized zirconia coatings were deposited by air plasma spraying. The microstructure of nanostructured and the conventional coating was studied after laser remelting. It has shown that formed a network of micro-cracks and pits after laser remelting on nanostructured coatings. With the decrease of the laser scanning speed, mesh distribution of micro cracks was gradually thinning on nanostructured coatings. Compared with conventional ceramic layers, the mesh cracks of nanostructured coating is dense and the crack width is small.
\end{abstract}

\section{Introduction}

Titanium is an important structural materials and functional materials, is the most widely used material on the engine [1]. Titanium has a low density, high strength, wide operating temperature range and excellent corrosion resistance and other characteristics. The maximum operating temperature range of titanium is only about $600{ }^{\circ} \mathrm{C}$ affected by high temperature oxidation [2]. Thermal barrier coating is an advanced high-temperature protective coating. It has a wide range of research and application background in the aerospace [3]. The preparation of thermal barrier coatings on titanium alloy surface not only can make parts lighter, but also can be effectively insulated thermal barrier coatings and

* Corresponding author:wdh@sues.edu.cn 
antioxidant protection. Thereby improving the antioxidant capacity of titanium alloys, blocking temperature invasion significantly improve the short-term use temperature of titanium alloy [4]. Plasma spraying powder quality directly affects the coating performance. Therefore, the quality of powders of is a very important factor for plasma sprayed nanostructured Coating. Due to the small powder particle size, large specific surface area, light weight, small inertia and poor mobility, spraying process is easy to drift, low rate of deposition on the surface of the substrate, to form a dense coating. Therefore, it is necessary to undertake handling first, agglomerated into micron powders with nanostructure. Compared with the conventional ceramic, nanostructured ceramic has low coefficient of thermal conductivity, thermal expansion coefficient and high stability under high temperature, low elastic modulus, combined with the characteristics of higher strength. However, there are micro defects in the plasma spraying layer with residual stress and micro cracks. The laser surface technology is rapid developing in recent years. High energy density laser beam interacts with the surface material, which can cause changed of the material physical state, composition, phase composition and microstructure. So as to realize the material surface modification in high thermal barrier coating performance, laser surface remelting composite coating technology has caused the attention of researchers.

\section{Materials and Methods}

By atmospheric plasma spraying method, the nanoscale and conventional thermal barrier coatings were prepared. Test substrates made of titanium alloy TC11, processed into size rectangular specimens of $15 \mathrm{~mm} \times 12 \mathrm{~mm} \times 3 \mathrm{~mm}$, corner the arc over $(\mathrm{r}=2 \mathrm{~mm})$. The adhesive layer thickness is about $100 \mu \mathrm{m}$ and the thickness of ceramic layer is about $300 \mu \mathrm{m}$ in plasma spraying. In order to preserve a part of the powder's nanostructure and achieve the necessary physical condition for cohesion and adhesion, the spraying parameters have been optimized to partially melt the powder particles during plasma spraying. The spraying parameters are listed in Table 1.

The industrial remelting equipment for plasma sprayed nanostructured thermal barrier coating was large power $(15 \mathrm{KW}) \mathrm{CW} \mathrm{CO}$ laser system. The processing parameters of laser remelting on nanostructured thermal barrier coatings used are shown in Table 2.

TABLE 1 THE ATMOSPHERIC PLASMA SPRAYING PROCESSING PARAMETERS FOR TITANIUM ALLOY SURFACE.

\begin{tabular}{|c|c|c|c|}
\hline Coatings & NiCrAlY & Conventional YPSZ & Nanostructured YPSZ \\
\hline Current $[\mathrm{A}]$ & 480 & 510 & 480 \\
\hline Voltage [V] & 65 & 75 & 75 \\
\hline Primary gas, $\operatorname{Ar}\left[1 \cdot \mathrm{min}^{-1}\right]$ & 37 & - & \\
\hline Primary gas, $\mathrm{N}_{2}\left[1 \cdot \mathrm{min}^{-1}\right]$ & - & 37 & 37 \\
\hline $\begin{array}{l}\text { Secondary } \quad \text { gas, } \\
{\left[1 \cdot \mathrm{min}^{-1}\right]}\end{array}$ & 5 & 5 & 5 \\
\hline Carrier gas, $\operatorname{Ar}\left[1 \cdot \mathrm{min}^{-1}\right]$ & 3.5 & 3 & 3 \\
\hline $\begin{array}{l}\text { Powder feeding rate } \\
{\left[\mathrm{g} \cdot \mathrm{min}^{-1}\right]}\end{array}$ & 54.4 & 10.4 & 10.4 \\
\hline $\begin{array}{l}\text { Torch traverse speed } \\
{\left[\mathrm{mm} \cdot \mathrm{s}^{-1}\right]}\end{array}$ & 10 & 6 & 6 \\
\hline $\begin{array}{l}\text { Substrate rotation speed } \\
{[\mathrm{rpm}]}\end{array}$ & 26 & 26 & 26 \\
\hline Stand off distance $[\mathrm{mm}]$ & 100 & 60 & 60 \\
\hline Coating thickness $[\mu \mathrm{m}]$ & 100 & $300-500$ & $300-500$ \\
\hline
\end{tabular}

The microstructures of the powders and the as-sprayed nanostructures zirconia coatings were characterized with a transmission electron microscope (TEM, Model, JEM-2010, 
Tokyo, Japan) and a field emission scanning electron microscope (FESEM, Model FEI Sirion200, USA).

TABLE 2 LASER PROCESSING PARAMETERS FOR THE SURFACE LASER-GLAZING OF TBC.

\begin{tabular}{ll}
\hline \multicolumn{1}{c}{ Wave type } & Continuous \\
\hline Wave length $(\mu \mathrm{m})$ & 10.6 \\
Raw beam size $(\mathrm{mm})$ & 25 \\
Focal length $(\mathrm{mm})$ & 357 \\
Focal point diameter $(\mathrm{mm})$ & 0.7 \\
Defocus distance $(\mathrm{mm})$ & 120 \\
Glazing beam diameter $(\mathrm{mm})$ & 8.4 \\
Power $(\mathrm{W})$ & 3,500 \\
\hline
\end{tabular}

\section{Results and Discussion}

\subsection{Surface Morphology of Ceramic Coatings by Plasma Spraying}

The surface morphology of conventional ceramic layer was shown in Figure 1. The unmelted particles were shown on the roughness surface. The molten droplet spreading formation layer and surface connected pores also can be seen in the figure 1(a). As shown in figure 1(b), due to rapid cooling, which forming of quenching molten particles to thermal stress, causing micro cracks in generating plasma spraying process.

The surface morphology of nanostructured coatings was shown in figure 2 . The surface of the nano-ceramic layer is also relatively rough, as shown in the figure 2(a). The unmelted particles were shown on the roughness surface. The molten droplet spreading formation layer and surface connected pores also can be seen in the figure 2(a). But compared with the micro cracks on the conventional coating, the micro cracks on the surface of the nano-ceramic layer are small, and the distribution is sparse.
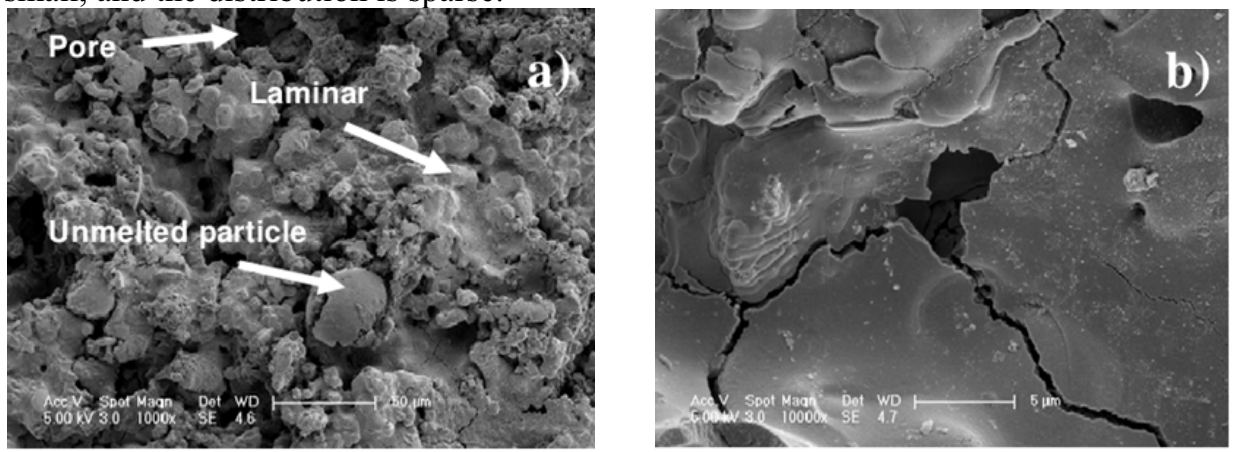

Figure 1. SEM images of top surface of the as-sprayed conventional coatings at different magnification. a) $1000 \times$; b) $10000 \times$. 

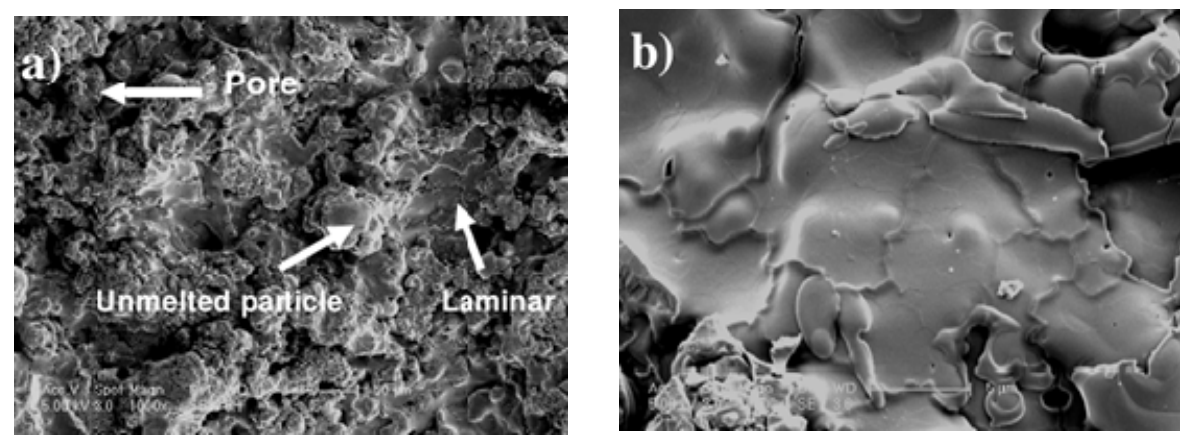

Figure 2. SEM images of top surface of the as-sprayed nanostructured coatings at different magnification. a) $1000 \times$; b) $10000 \times$.

\subsection{Surface Morphology of Laser Remelting Samples}

As shown in Figure 3, the surface morphology of the Nano-ceramic coating in laser remelting region and non remelting region are compared. In the process of laser treatment, the integrity of the surface of the ceramic is not destroyed, and the boundary of the remelting area and the non remelting region is maintained. In the continuous state, the surface of the non re melting area is still loose, and the microstructure of the coating is rough. The surface of laser remelting area is dense and smooth, with obvious sealing effect. But net vertical micro cracks inevitable appeared on the surface.

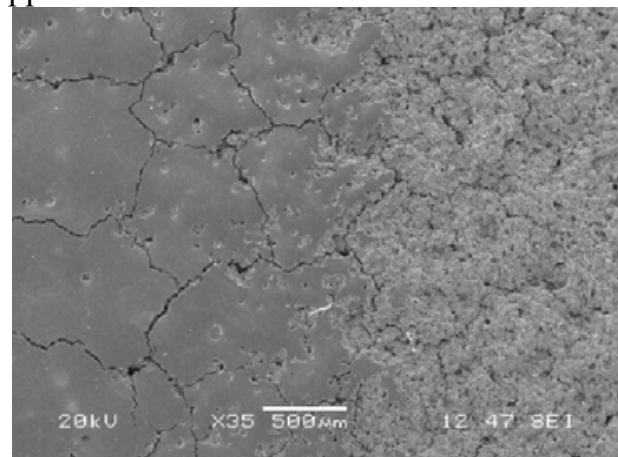

Figure 3. SEM Micrograph illustrating the contrast of surface morphology in a region containing both laser treated (left) and untreated (right) nano-coating.
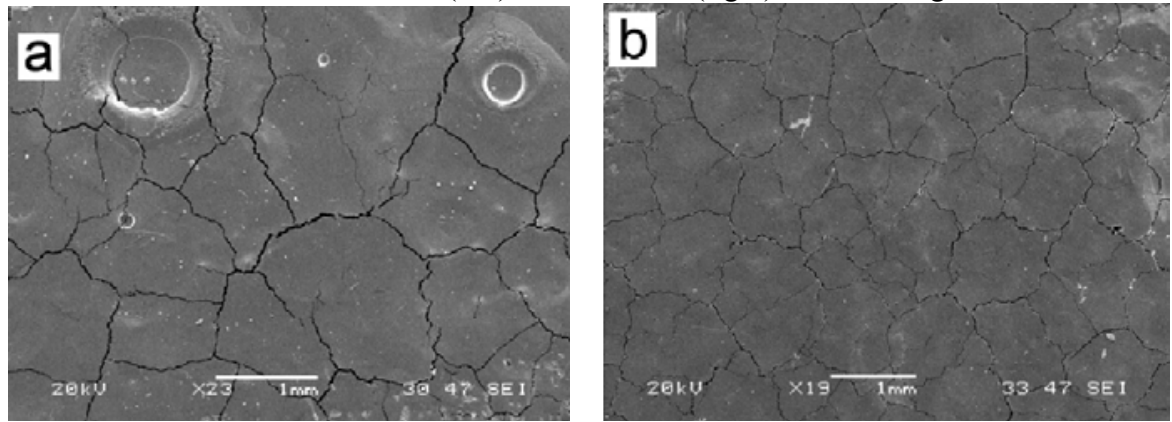

Figure 4 SEM micrographs of the top surfaces of the laser-glazed coatings; (a) the conventional coating; (b) the nanostructure coating.

The whole surface morphology of Nano and conventional ceramic coatings after laser remelting is shown in figure 4. It is shown that the surface is full of the mesh micro cracks on the whole area after laser remelting. The micro cracks are perpendicular to the coating surface, and are irregular in shape. Compared with the conventional ceramic layer, the mesh 
crack is more compact and the crack width is smaller on the surface of the nano-ceramic layer. The distribution of the mesh micro cracks is found in the two types of coatings, changes gradually sparse. The micro crack cracking degree becomes larger.
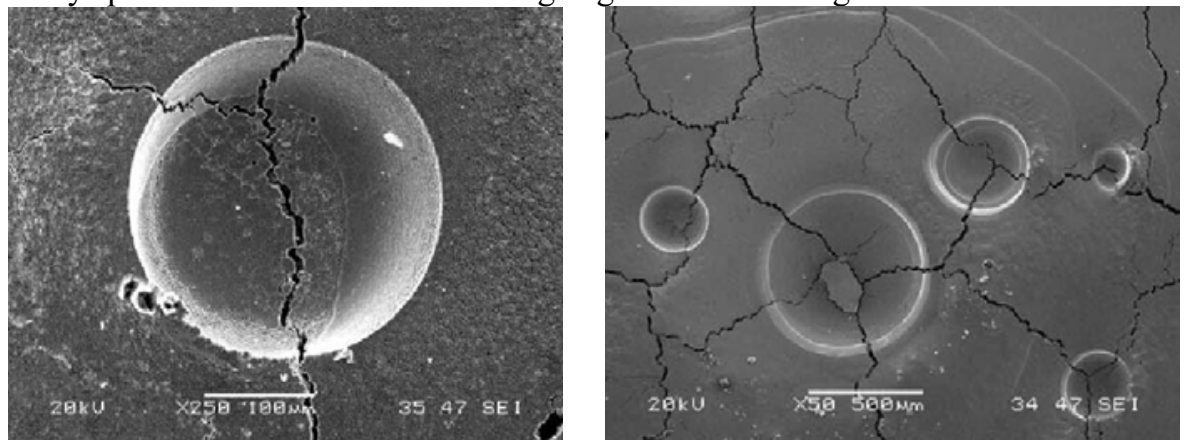

Figure 5 The drop pit at the surface of the laser-glazed conventional TBCs

After laser remelting, the surface of ceramic coating appeared visible pits, as shown in figure 5. The pits is related to the state of the plasma spraying process, the air is involved in making the coating loose, containing more pores. Under the same laser parameters, the number of pits on the surface of the ceramic layer is more than that of the nano ceramic layer. It is also observed that most of the pits are connected with the micro cracks in figure 5. It shows that the gas in the pores is one of the reasons for the formation of the crack during the rapid heating and cooling of the laser.

\section{Conclusions}

Nanostructure thermal barrier coatings were applied on the titanium alloy by air plasma spraying. Conventional counterparts which were used for comparison were fabricated as well. Plasma-sprayed conventional and nanostructure ceramic coatings have been subjected to laser-glazing processes which provide a remelting and subsequent solidification of the surface. The results revealed that laser-glazing carried out on plasma-sprayed zirconia coatings has brought in a smooth and dense glazed surface with craters and a network of micro cracks. The micro crack network in the conventional coating is sparser than that in the nanostructure coating.

\section{Acknowledgements}

This research was supported by the Foundation of Shanghai University of Engineering Science (cz1505010), School level start-up fund 2015-09 of Shanghai University of Engineering Science part by grants from Research project of Shanghai science and technology committee,China (Grant No. 14521102902) and Research Project of Joint Research Center for Advanced Aerospace Technology of SAST-SJTU (Grant No. USCAST2013-20).

\section{References}

1. M. Lugovy, V. Slyunyayev, V. Teixeira: Surf. Coat. Technol. Vol. 184 (2004), p.332.

2. P.C. Tsai, C.S. Hsu: Surf. Coat. Technol. Vol. 183 (2004), p.30.

3. K.M. Jasim, R. Dawtings, D. West: J. Mater. Sci. Vol. 27(1992), p. 3903.

4. T. A. Talor, P. N. Walsh: Surf. Coat. Tech. Vol. 177-178 (2004), p. 25.

5. K. Landes: Surf. Coat. Technol.. Vol. 205 (2006), p. 1950. 